\title{
Cognitive and affective control
}

\section{Gilles Pourtois, Wim Notebaert and Tom Verguts*}

Department of Psychology, Ghent University, Ghent, Belgium

*Correspondence: tom.verguts@ugent.be

Edited by:

Lorenza S. Colzato, Leiden University, Netherlands

Reviewed by:

Lorenza S. Colzato, Leiden University, Netherlands

Traditionally, cognition and emotion are seen as separate domains that are independent at best and in competition at worst. The French scientist and philosopher Blaise Pascal (1623-1662) famously said "Le coeur a ses raisons que la raison ne connaît point" (The heart has its reasons that reason does not know). Consistent with this quote, many studies in the past have underscored dissociable effects and non-overlapping brain structures of affect and cognition during the control and monitoring of goal-directed behavior (e.g., Bush et al., 2000). Over the last century, however, psychologists and neuroscientists have increasingly appreciated strong reciprocal connections and interactions between cognition and emotion. Initially this was demonstrated in cognitive functions such as perception, attention, learning, memory and decision-making. For instance, an emotional stimulus can alter low-level visual perception (e.g., Bocanegra and Zeelenberg, 2009), and it can capture attention (e.g., Anderson and Phelps, 2001). Likewise, emotional stimuli are better learned and remembered than neutral ones (e.g., McGaugh, 1990) and they can provide strong incentives to bias decision-making (Bechara et al., 1997).

Hence, the independent or competitive view is gradually being replaced by an interactive view. Currently, we focus on interactions of emotion and motivation with cognitive control. Empirical articles and review papers included in this Research Topic timely reveal the extent of overlap and synergistic effects between cognitive control and a wide range of affective processes, both in the normal adult brain, as well as in specific (pathological) conditions, best characterized by either poor or unripe prefrontal-based executive functions as well as impaired affective processes.

Broadly speaking, the original contributions included in this Research Topic tackle one (or more) out of three possible topics. The first and most represented consists of the influence of emotion on cognitive control. Krypotos et al. (2011) focus on the effect of individual differences in emotion regulation, measured by heart rate variability, on response inhibition. van Steenbergen et al. (2011) demonstrate attentional focusing after the presentation of negative pictures. Stürmer et al. (2011) discuss the effect of reward on conflict adaptation. Ridderinkhof et al. (2012) showed that positive affect restored decision learning in patients with Parkinson's disease. Reeck and Egner (2011) demonstrated that irrelevant emotional information distracts more than non-emotional information, supporting affective prioritization in human information processing. Demanet et al. (2011) study the effect of affective stimuli on voluntary task switching. Cavanagh et al. (2011) show that depression is associated with larger error (ERN) signals, suggesting an influence of motivational state on early error processing. Danielmeier and Ullsperger (2011) study the effect of errors (motivationally salient events) on post-error processing. Finally, Chiew and Braver (2011) review the influences of motivational state on early error processing.

In the second category, papers establish a conceptual or anatomical common substrate for cognitive control and emotion. Lowe and Ziemke (2011) endorse a perspective in which emotions are predictions of action tendencies. Aarts et al. (2011) review the literature supporting the hypothesis that (striatal) dopamine regulates the interaction between (appetitive) motivation and cognition. Mushtaq et al. (2011) look at similarities between uncertainty and cognitive control. Mueller (2011) reviews the developmental trajectories of cognitive and emotion control during adolescence. Berggren et al. (2011) emphasize the link between trait-related distractibility in healthy adults and their performance in standard cognitive tasks. Tops and Boksem (2011, 2012) propose that there are two cognitive control systems (one ventral and one dorsal), both of which are partially cognitive and partially affective. Su et al. (2011) propose the glance-look model, specifying how affect and cognitive control interact to produce the attentional blink.

In the third category, a relatively modest number of papers look at the influence of cognitive control on emotion. Krämer et al. (2011) demonstrate a correlation between cognitive control and aggression, suggesting an influence of the former on inhibiting the latter. The paper by Schmidt et al. (2011) reviews the effect of cognitive control on inhibition of thoughts for (being able to) sleep. Paret et al. (2011) demonstrate how cognitive control plays an important role in complex affective processes, such as emotion regulation and the reappraisal of our emotional life. Huizenga et al. (2012) investigate how repeated application of cognitive control influences motivational processing. Finally, the paper by Danielmeier and Ullsperger (2011) investigates the aftereffects of making an error.

In all, the main contribution of this special issue is to highlight similarities and reciprocal influences between cognitive control and emotion. Rather than separate modules, the papers gathered in this special issue concur in suggesting that emotion and cognitive control are two sides of the same coin, as they both contribute, through synergistic effects, to the optimization of behavior. As such, this special issue emphasizes the need to move beyond the classical division or dichotomy between cognitive control and emotion in order to model and account for human goal-directed behavior across various tasks and situations. 


\section{REFERENCES}

Aarts, E., van Holstein, M., and Cools, R. (2011). Striatal dopamine and the interface between motivation and cognition. Front. Psychology 2:163. doi: 10.3389/fpsyg.2011.00163

Anderson, A. K., and Phelps, E. A. (2001). Lesions of the human amygdala impair enhanced perception of emotionally salient events. Nature 411, 305-309.

Bechara, A., Damasio, H., and Tranel, D. (1997). Deciding advantageously before knowing the advantageous strategy. Science 275, 1293-1295.

Berggren, N., Hutton, S. B., and Derakshan, N. (2011). The effects of self-report cognitive failures and cognitive load on antisaccade performance. Front. Psychology 2:280. doi: 10.3389/fpsyg.2011.00280

Bocanegra, B. R., and Zeelenberg, R. (2009). Emotion improves and impairs early vision. Psychol. Sci. 20, 707-713.

Bush, G., Luu, P., and Posner, M. (2000). Cognitive and emotional influences in anterior cingulate cortex. Trends Cogn. Sci. 4, 215-222.

Cavanagh, J. F., Bismark, A. J., Frank, M. J., and Allen, J. J. (2011). Larger error signals in major depression are associated with better avoidance learning. Front. Psychology 2:331. doi: 10.3389/fpsyg.2011.00331

Chiew, K. S., and Braver, T. S. (2011). Positive affect versus reward: emotional and motivational influences on cognitive control. Front. Psychology 2:279. doi: 10.3389/fpsyg.2011.00279

Danielmeier, C., and Ullsperger, $\mathrm{M}$. (2011). Post-error adjustments. Front. Psychology 2:233. doi: 10.3389/fpsyg.2011.00233
Demanet, J., Liefooghe, B., and Verbruggen, F. (2011). Valence, arousal, and cognitive control: a voluntary task-switching study. Front. Psychology 2:336. doi: 10.3389/fpsyg.2011.00336

Huizenga, H. M., van der Molen, M. W., Bexkens, A., Bos, M. G. N., and van den Wildenberg, W. P. M. (2012). Muscle or motivation? A stop-signal study on the effects of sequential cognitive control. Front. Psychology 3:126. doi: 10.3389/fpsyg.2012. 00126

Krämer, U. M., Kopyciok, R. P., Richter, S., Rodriguez-Fornells, A., and Münte, T. F. (2011). The role of executive functions in the control of aggressive behavior. Front. Psychology 2:152. doi: 10.3389/fpsyg.2011.00152

Krypotos, A.-M., Jahfari, S., van Ast, V. A., Kindt, M., and Forstmann, B. U. (2011). Individual differences in heart rate variability predict the degree of slowing during response inhibition and initiation in the presence of emotional stimuli. Front. Psychology 2:278. doi: 10.3389/fpsyg.2011. 00278

Lowe, R., and Ziemke, T. (2011). The feeling of action tendencies: on the emotional regulation of goal-directed behavior. Front. Psychology 2:346. doi: 10.3389/fpsyg.2011.00346

McGaugh, J. L. (1990). Significance and remembrance: the role of neuromodulatory systems. Psychol. Sci. 1, 15-26.

Mueller, S. C. (2011). The influence of emotion on cognitive control: relevance for development and adolescent psychopathology.
Front. Psychology 2:327. doi: 10.3389/fpsyg.2011.00327

Mushtaq, F., Bland, A. R., and Schaefer, A. (2011). Uncertainty and cognitive control. Front. Psychology 2:249. doi: 10.3389/fpsyg.2011. 00249

Paret, C., Brenninkmeyer, J., Meyer, B., Yuen, K. S., Gartmann, N., Mechias, M. L., et al. (2011). A test for the implementationmaintenance model of reappraisal. Front. Psychology 2:216. doi: 10.3389/fpsyg.2011.00216

Reeck, C., and Egner, T. (2011). Affective privilege: asymmetric interference by emotional distracters. Front. Psychology 2:232. doi: 10.3389/fpsyg.2011.00232

Ridderinkhof, K. R., van Wouwe, N. C., Band, G. P. H., Wylie, S. A., Van der Stigchel, S., van Hees, P., et al. (2012). A tribute to Charlie Chaplin: induced positive affect improves reward-based decision-learning in Parkinson's disease. Front. Psychology 3:185. doi: 10.3389/fpsyg.2012. 00185

Schmidt, R. E., Harvey, A. G., and Van der Linden, M. (2011). Cognitive and affective control in insomnia. Front. Psychology 2:349. doi: 10.3389/fpsyg.2011.00349

Stürmer, B., Nigbur, R., Schacht, A., and Sommer, W. (2011). Reward and punishment effects on error processing and conflict control. Front. Psychology 2:335. doi: 10.3389/fpsyg.2011. 00335

Su, L., Bowman, H., and Barnard, P. (2011). Glancing and then looking: on the role of body, affect, and meaning in cognitive control. Front. Psychology
2:348. doi: 10.3389/fpsyg.2011. 00348

Tops, M., and Boksem, M. A. S. (2011). A potential role of the inferior frontal gyrus and anterior insula in cognitive control, brain rhythms, and event-related potentials. Front. Psychology 2:330. doi: 10.3389/fpsyg.2011. 00330

Tops, M., and Boksem, M. A. S. (2012). "What's that?" "What went wrong?" Positive and negative surprise and the rostral-ventral to caudal-dorsal functional gradient in the brain. Front. Psychology 3:21. doi: 10.3389/fpsyg.2012. 00021

van Steenbergen, H., Band, G. P. H., and Hommel, B. (2011). Threat but not arousal narrows attention: evidence from pupil dilation and saccade control. Front. Psychology 2:281. doi: 10.3389/fpsyg.2011. 00281

Received: 11 October 2012; accepted: 17 October 2012; published online: 02 November 2012.

Citation: Pourtois G, Notebaert $W$ and Verguts T (2012) Cognitive and affective control. Front. Psychology 3:477. doi: 10.3389/fpsyg.2012.00477

This article was submitted to Frontiers in Cognition, a specialty of Frontiers in Psychology.

Copyright (C) 2012 Pourtois, Notebaert and Verguts. This is an open-access article distributed under the terms of the Creative Commons Attribution License, which permits use, distribution and reproduction in other forums, provided the original authors and source are credited and subject to any copyright notices concerning any third-party graphics etc. 